\title{
Depressive symptom clusters among the elderly: a longitudinal study of course and its correlates
}

\begin{abstract}
BACKGROUND
The longitudinal course of depressive symptoms among the elderly was examined over a one-month follow-up period. The aim of the study was to identify clusters of change as well as their correlates, including demographic variables and coping strategies (brooding, reflection, co-rumination, and positive reappraisal).
\end{abstract}

\section{PARTICIPANTS AND PROCEDURE}

Two hundred and seventy-seven seniors (age $77.39 \pm 9.20$ years, $67.50 \%$ women) were assessed twice within one month with the 11-item version of the Centre for Epidemiological Studies Depression Scale. Demographic and clinical characteristics were measured at baseline together with coping strategies. Selected items from Ruminative Response Styles (brooding, reflection), the Co-Rumination Questionnaire (co-rumination), and mini-COPE (positive reframing) were used.

\section{RESULTS}

On the basis of a two-step cluster analysis, four clusters of depression course were recognized: low stable $(n=53)$, medium stable $(n=101)$, high increasing $(n=69)$, and very high stable $(n=54)$. Multinomial logistic regression analyses showed that higher number of diseases, higher brooding and lower positive reappraisal were associated with increased likelihood of belonging to the higher symptom groups. No significant gender effect was noted.

\section{CONCLUSIONS}

A non-clinical sample of older people appeared to be heterogeneous regarding symptoms of depression and its course. However, only $19.00 \%$ of participants reported a low level of depression. Strategies of coping with health concerns may play a significant role here, as brooding and positive reappraisal significantly differentiate between clusters of low stable and high stable symptoms, even after control for a proxy of objective health status.

KEY WORDS

coping; depression; elderly; cluster analysis; longitudinal study

ORgANizATIONS - Department of Psychology, University of Social Sciences and Humanities, Warsaw, Poland AUthors' CONTRIBUtion - A: Study design - B: Data collection - C: Statistical analysis - D: Data interpretation .

E: Manuscript preparation · F: Literature search · G: Funds collection

CORResponding AUthor - Aleksandra Kroemeke, Ph.D., Department of Psychology, University of Social Sciences and

Humanities, 19/31 Chodakowska Str., 03-815 Warsaw, Poland, e-mail: akroemeke@swps.edu.pl

TO CITE THIS ARTICLE - Kroemeke, A., \& Gruszczyńska, E. (2014). Depressive symptom clusters among the elderly:

a longitudinal study of course and its correlates Health Psychology Report, 2(4), 269-279. DOI: 10.5114/hpr.2014.46694 


\section{BACKGROUND}

The European population is ageing. During the next 50 years there will be 130 million people over 65 years of age living in Europe, which means that the proportion of this age group in the general population will increase from 17 to about $30.00 \%$ (Rechel et al., 2013). It is estimated that by 2020 approximately $24.00 \%$ of the Polish population will be at least 60 years old (Central Statistical Office, 2009). Ageing of soci-
Aleksandra Kroemeke, Ewa Gruszczyńska eties is therefore becoming a problem with complex social, economic, medical and cultural consequences (Steuden, 2011).

Mental well-being of senior citizens is hence one of the key issues, since in Poland only $1.60 \%$ of individuals over 65 years of age maintain a relatively high quality of life, which is the lowest ratio among $15 \mathrm{Eu}-$ ropean countries (Hank, 2011). The problem of low mood seems to be the most important one, because the same studies indicate the highest level of depressive symptoms among Polish women (Börsch-Supan et al., 2008). Therefore, although their life expectancy is higher than in the case of men (Central Statistical Office, 2013) and similar to the European average (EUROSTAT, 2010), it is rather a miserable life in old age - at least according to the self-descriptive data. Also the data provided by the Global Age Watch Index (HelpAge International, 2013) confirm the extremely bad condition of mental health among elderly Poles. What is more, it cannot be explained simply by socioeconomic factors, because Poland is ranked quite high in these terms (see Health status - 87 vs. Income security - 20, Employment and education - 54, Enabling societies and environment - 43; the ranking included 91 countries, ibid.). Hence other conditions of this state of affairs have to be searched for.

It is commonly found that among elderly people many chronic diseases appear (multimorbidity, Kirchberger et al., 2012) and that they are difficult be medically controlled, even if the patient is genuinely committed. It is therefore reasonable to expect that cognitive efforts which aim at coping with what is objectively hard to change will be essential for the patient's mental well-being. While discussing the connection between such a strategy and depression, one should above all consider ruminations and positive reappraisal; when confronted with empirical findings, the former appear as ineffective while the latter - as an effective way to improve one's mood.

That is because ruminations, i.e. focusing one's attention on negative emotions, their possible causes and unsolicited consequences (Lyubomirsky \& Nolen-Hoeksema, 1993), is a well documented predictor of low mood and clinical depression (Lyubomirsky \& Tkach, 2003; Nolen-Hoeksema, Wisco, \& Lyubomirsky, 2008; Watkins, 2008), including among the elderly (Kraaij, Pruymboom, \& Garnefski, 2002; Thom- sen, Mehlsen, Viidik, Sommerlund, \& Zachariae, 2005). However, claiming that every case of focusing on negative emotions leads to negative consequences would be a simplification. Therefore, ruminations are divided into brooding and reflection (Treynor, Gonzalez, \& Nolen-Hoeksema, 2003). The differentiation criterion is first of all a passive or active processing and the degree of subjective control over it. In the case of brooding, an individual dwells on their situation and compares it to currently inaccessible standards in a passive, uncontrollable way. In contrast, reflection is a way of cognitive coping oriented at drawing constructive conclusions for the future. Empirical studies confirm this differentiation, in reference to both the structure of measurement tools (Treynor et al., 2003; Schoofs, Heramans, \& Raes, 2010; Withmer $\&$ Gotlieb, 2011) and psychological effects (Burwell \& Shirk, 2007; Ciesla \& Roberts, 2002; Gooding, Taylor, \& Tarrier, 2012; Marroquín, Fontes, Scilletta, \& Miranda, 2010), although empirical results are less unequivocal in the case of the latter. Therefore, reflection can also be a different, more cognitively advanced, kind of rumination, and so it is often considered (Schoofs et al., 2010). In addition, few studies have explored this differentiation among the elderly (see Rewston, Clarke, Moniz-Cook, \& Waddington, 2007).

Another issue is the relation between positive reappraisal and reflection. The former refers to such reformulation of the way of thinking about a stressor that it is assigned a positive meaning, which changes the emotional response (Gross, 1998; Folkman \& Moskowitz, 2000). In turn, a definition of reflection assumes neither a change in the perception of a stressor nor a change in the emotional state. However, both strategies can be expected to be connected to some extent, because they both intentionally involve cognitive resources, although their function in the emotional regulatory process remains distinct (Brans, Koval, Verduyn, Lim, \& Kuppens, 2013). Among the elderly, research has shown that positive reappraisal is related to depressive symptoms (Garnefski \& Kraaij, 2006), even after controlling their former level and the number of experienced negative events (Kraaij et al., 2002). It is confirmed by the adaptive effects of this coping strategy, well recognized in the empirical studies (Helgeson, Reynolds, \& Tomich, 2006). Even though, some of these effects have been limited to uncotrollable conditions (Troy, Shallcross, \& Mauss, 2013), but health problems in old age are generally of this nature (World Health Organization, 2011).

Recently research has adopted a new topic - so called co-ruminations. They add a social dimension to ruminations. Therefore ruminations refer to interpersonal strategies, as co-ruminations include intense analysis and discussion of one's own problems and the accompanying negative emotions with other people; the dominant issue is concentration on recurring unsolicited aspects (Rose, 2002). Most studies 
in this area have focused on adolescents and young adults, and no research has been conducted among the elderly so far. It seems that this construct may be especially useful in this case, since there is a kind of social exchange called 'complaining' (Alicke et al., 1992), including complaining about various kinds of physical ailments. As such it seems more accurate to operationalize it as co-ruminations, since then this behaviour is included in the paradigm of stress and coping (Lazarus \& Folkman, 1984) and can be considered as one of the sociable coping strategies. The consequences of co-rumination are not unequivocal; on the one hand it is related to rumination and has similar maladaptive effects; on the other hand, it may enhance the intimacy with a person with whom one co-ruminates (see Rose, Carlson, \& Waller, 2007).

Affective states have their own dynamics. When diagnosing depression, the time criterion includes a one-month period (see ICD-10, World Health Organization, 1992). Hence it can be assumed that this time period is sufficient to observe significant mood changes. However, an assumption that the whole study group undergoes identical changes is considered to be a simplification. Instead, homogeneous sub-populations are differentiated, and each of them is described using a different change pattern (see Bonanno, Kennedy, Galatzer-Levy, Lude, \& Elfström, 2012).

In the light of the above considerations, three research aims were formulated:

1. Differentiating clusters of change, based on the dynamics of depression during the previous month.

2. Defining sociodemographic correlates of these clusters membership; it is assumed that female gender and multimorbidity will correlate with belonging to the cluster of high intensity of depressive symptoms.

3. Identifying the relation between the discussed emotion-focused coping strategies, and the clusters of change. It is expected that the low positive reappraisal and high rumination and co-rumination will be associated with belonging to the cluster of high depressive symptoms.

\section{PARTICIPANTS AND PROCEDURE}

Participants were 277 elderly people (67.50\% of women) aged 60-100 years $(M=77.39, S D=9.20)$. They were patients in residential medical care facilities (65.00\% of the participants; range of stay from 1 to 303 months, $M=61.93$ months, $S D=59.84)$ and daily Seniors' Clubs (35.00\% of the participants). The sample selection criteria were age $(\geq 60)$ and the lack of cognitive disorders (no diagnosis of dementia or mild cognitive impairments $[\mathrm{MCI}]$ in the medical history, and efficient cognitive functioning of the respondents, confirmed by the care facility personnel). The study group included mostly single individuals (un- married, widowed, divorced; $83.00 \%$ ), with secondary or primary education $(71.00 \%)$, not having used medical care for the previous 6 months $(63.00 \%)$, describing their material status as average $(62.00 \%)$. The respondents suffered from more than four coexisting chronic illnesses $(0-12 ; M=4.53, S D=2.63)$; they took on average about six medicines per day $(M=6.42$, $S D=4.47)$. Their mean Body Mass Index (BMI) was $27.13(S D=5.19,15.24-52.07)$, which indicated that they were rather overweight. The institution did not differentiate the participants in terms of controlled variables, with the exception of age and the number of administered drugs: the patients of residential medical care facilities $\left(M_{\text {age }}=79.14, S D=9.07\right)$ were significantly older than the elderly attending the daily Seniors' Clubs $\left(M_{\text {age }}=74.15, S D=8.60\right.$, $t(275)=4.44, p<.001)$ and took significantly more drugs daily $(t(271)=2.22, p=.050, M=6.78, S D=4.33$ and $M=5.57, S D=4.15$ respectively).

The research was longitudinal and included three measurements at monthly intervals and six months after the initial measurement. This paper presents the data gathered during the first two phases. The second phase included 193 seniors, which amounts to $69.70 \%$ of the original sample $(61.70 \%$ and $38.30 \%$ of respondents from residential medical care facilities and daily Seniors' Clubs respectively). The missing data were random; Little's MCAR test: $\chi^{2}(3)=0.50, p=.778$.

The project received a positive opinion of the ethics committee (no. 22/2012). Participation was voluntary, after informed consent. Taking into consideration the specificity of the study group, abbreviated or experimental versions of the research tools were used (consisting of 2-6 items).

The number of depressive symptoms was measured using 11 items of the Centre for Epidemiological Studies Depression Scale (CES-D; Radloff, 1977; Polish adaptation: Dojka, Górkiewicz, \& Pająk, 2003; Ziarko, Kaczmarek, \& Haładzińki, 2012), assessed on a four-point scale from 0 (rarely or never) to 3 (often). The higher the result, the greater is the number of depressive symptoms.

Four kinds of cognitive strategies of coping with health problems were analysed: brooding, reflection, co-rumination and positive reappraisal. Ruminations (e.g. I think "Why do I have health problems other peoples don't have"?) and reflection (e.g. I think about why I feel this way) were measured using four Ruminative Response Styles items, which were modified for the purposes of this study (RRS; Treynor et al., 2003; Whitmer \& Gotlib, 2011). Co-ruminations (e.g. When I talk with someone I tell him/her every detail about my health problems) were measured using two Co-Rumination Questionnaire items, modified for the purposes of this study (Rose, 2002). Positive reappraisal (e.g. I've been trying to see it in a different light, to make it seem more positive) were measured using two Mini-COPE questionnaire items (Carver,
Depressive symptom clusters among the elderly 
Aleksandra Kroemeke, Ewa Gruszczyńska
1997; Polish adaptation: Juczyński, 2009). All statements was assessed on a four-point scale from 1 (no [untrue]) to 4 (yes [true]). The higher the results, the greater is the intensity of a given strategy.

All of the used tools had acceptable reliability coefficients (see Table 1), taking the double-item nature of some of them into consideration. For depression, results from both measurements were reported, while for other variables, only values obtained from the first measurement were taken into account.

First of all, missing data (concerning only depressive symptoms) were supplemented using the expectation-maximization (EM) method. The EM algorithm is an iterative procedure that produces maximum likelihood estimates, independent of the data loss character (random or not random) (Graham, 2009). Clusters of depressive symptom changes (from $\mathrm{t} 1$ to $\mathrm{t} 2$ ) were determined on the basis of two-step cluster analysis. The best solution was chosen based on Bayesian (BIC) and Aikaike (AIC) information criterion indicators, the ratio of distance measure, and the silhouette measure of cluster cohesion and separation. The best model should be characterized by the lowest criterion indicators and the greatest ratio of distance measure and cohesion. In accordance with the recommendations, the selection of the resultant model should be preceded by the analysis of all these indicators, accompanied by interpretation opportunities and theoretical integrity of the selected solution (Mooi \& Sarstedt, 2011). Next, it was tested whether demographic variables and coping strategies with health problems at time t1 were related to the membership to the given cluster of depressive symptom change (multiple logistic regression analysis; MLR). In MLR, the goodness of fit was assessed using Pearson's $\chi^{2}$, the parameters were estimated using the likelihood ratio $\left(\chi^{2}\right.$ statistics) for the whole model, the Wald $Z$-statistic value and the odds ratio (OR), for each independent variable. Apart from that, the moderating effect of the institution was checked. Explanatory variables were introduced using backward elimination; categori- cal variables were dummy coded. All analyses were conducted using SPSS 21.0.

\section{RESULTS}

Descriptive statistics of the variables and their correlations are presented in Table 1. A strong correlation was observed between depressive symptoms in time and brooding and reflection strategies. The other correlations were weak or moderate. The depressive symptoms increased significantly within one month in the whole group; Wilks' $\lambda F(1,276)=7.74, p=.006$.

Then, cluster analysis was conducted to differentiate homogeneous sub-groups of individuals differing in terms of the level of depressive symptoms in time. The results are presented in Table 2. The silhouette measure of cluster cohesion and separation revealed good fit for models with two, three and four clusters. Automatic determination of the number of classes indicated the two-cluster solution. However, this procedure was based solely on the ratio of distance measures (Arbuckle, 1995-2010). Other criterion indicators, AIC and BIC, indicated five- and four-cluster solutions respectively. Nevertheless, AIC overestimates and BIC underestimates (weakly) the correct number of clusters (Mooi \& Sarstedt, 2011). Hence it is recommended to compare both parameters and rely on the BIC value or on a lower number of clusters than could be concluded from the AIC value. Taking this into consideration, the four-cluster solution was adopted (see Fig. 1), since it was characterized by a lower BIC value, satisfactory AIC value (class $\mathrm{k}-1$, where $\mathrm{k}$ represents the class selected by AIC), goodness of fit of the model and the second largest ratio of distance measures.

The first cluster $(n=53,19.10 \%)$ comprised individuals with a relatively low, stable level of depressive symptoms during both measurements $\left(M_{1}=3.24\right.$, $S D_{1}=2.24, M_{2}=3.74, S D_{1}=2.16, F(1,52)=1.50$, $p=.226)$. The second, largest group $(n=101,36.50 \%)$ included individuals with a moderate, also stable

Table 1

Descriptive statistics, reliability indicators and Pearson's correlations among studied variables $(N=277)$

\begin{tabular}{|c|c|c|c|c|c|c|c|c|}
\hline & $M$ & $S D$ & $\alpha$ & 2. & 3. & 4. & 5. & 6. \\
\hline 1. CES-D & 10.78 & 6.12 & .77 & $.78^{* *}$ & $.34^{* *}$ & $.30^{* *}$ & $.15^{*}$ & $-.17^{*}$ \\
\hline 2. CES-D & 11.44 & 5.86 & .77 & & $.35^{* *}$ & $.32^{* *}$ & $.17^{*}$ & $-.14^{*}$ \\
\hline 3. Brooding ${ }_{1}$ & 3.37 & 2.16 & .67 & & & $.72^{* *}$ & $.43^{* *}$ & $.30 * *$ \\
\hline 4. Reflection $_{1}$ & 4.84 & 2.18 & .69 & & & & $.32^{* *}$ & $.21^{* *}$ \\
\hline 5. Co-rumination & 4.27 & 2.29 & .87 & & & & & $.29^{* *}$ \\
\hline 6. Positive Reappraisal & 5.48 & 1.99 & .66 & & & & & \\
\hline
\end{tabular}


Table 2

Clustering results - comparison of indices

\begin{tabular}{|c|c|c|c|c|c|}
\hline $\begin{array}{l}\text { Number of } \\
\text { clusters }\end{array}$ & $\begin{array}{c}\text { Average Silhouette } \\
\text { value }\end{array}$ & $\mathrm{AIC}$ & $\mathrm{BIC}$ & $\begin{array}{c}\text { Ratio of } \\
\text { distance measure }\end{array}$ & Cluster size $(n)$ \\
\hline 1 & & 391.00 & 405.50 & & 277 \\
\hline 2 & .06 & 242.23 & 271.23 & 3.16 & $161 / 116$ \\
\hline 3 & .05 & 243.31 & 286.80 & 1.52 & $53 / 120 / 104$ \\
\hline 4 & .05 & 170.92 & 228.90 & 2.04 & $53 / 101 / 69 / 54$ \\
\hline 5 & .05 & 168.44 & 240.92 & 1.38 & $45 / 60 / 62 / 56 / 54$ \\
\hline
\end{tabular}

level of symptoms $\left(M_{1}=8.55, S D_{1}=2.95, M_{2}=9.14\right.$, $\left.S D_{1}=1.99, F(1,100)=2.43, p=.122\right)$. The third cluster $(n=69,24.90 \%)$ included respondents with a relatively high level of symptoms, increasing with time $\left(M_{1}=12.79, S D_{1}=2.59, M_{2}=14.62, S D_{1}=2.76\right.$, $F(1,68)=11.24, p<.001)$. The last group $(n=54$, $19.50 \%)$ was characterized by a very high, stable level of depressive symptoms in time $\left(M_{1}=19.76, S D_{1}=3.38\right.$, $\left.M_{2}=19.25, S D_{1}=3.45, F(1,53)=0.80, p=.375\right)$.

Next, it was checked whether demographic and health-related variables were associated with belonging to the given cluster of symptoms (see Table 3). In accordance with the expectations, seniors' objective health (the number of illnesses and number of drugs administered daily) correlated with belonging to certain clusters; individuals with a high level of depressive symptoms were characterized by worse somatic health. In addition, groups with a high level of symptoms included mostly single people and the inhabitants of residential care facilities.

It was further analysed whether the strategies of coping with health problems (measured during the first measurement) were related to cluster membership. The rumination strategies (brooding, reflection) correlated strongly with each other $(r=.72$, $p<.001)$ and hence their collinearity was tested. As it was not confirmed (VIF: brooding $=2.35$; reflection $=$ 2.08; tolerance: brooding $=.43$; reflection $=.48$ ), they were both included in the analysis simultaneously ${ }^{1}$. Demographic and health-related variables which had differentiated the clusters significantly were included in the analysis as covariates. Table 4 presents the resultant model containing only those variables whose likelihood ratios turned out to be significant.

The analysis reveals that the number of illnesses and brooding and positive reappraisal were related to the allocation to certain clusters. In general: clusters with a higher level of depressive symptoms were related to higher brooding, lower positive reappraisal and higher multimorbidity. The only significant result concerning co-rumination was found in the comparison of clusters with high increasing symptoms and moderate stable symptoms. A higher

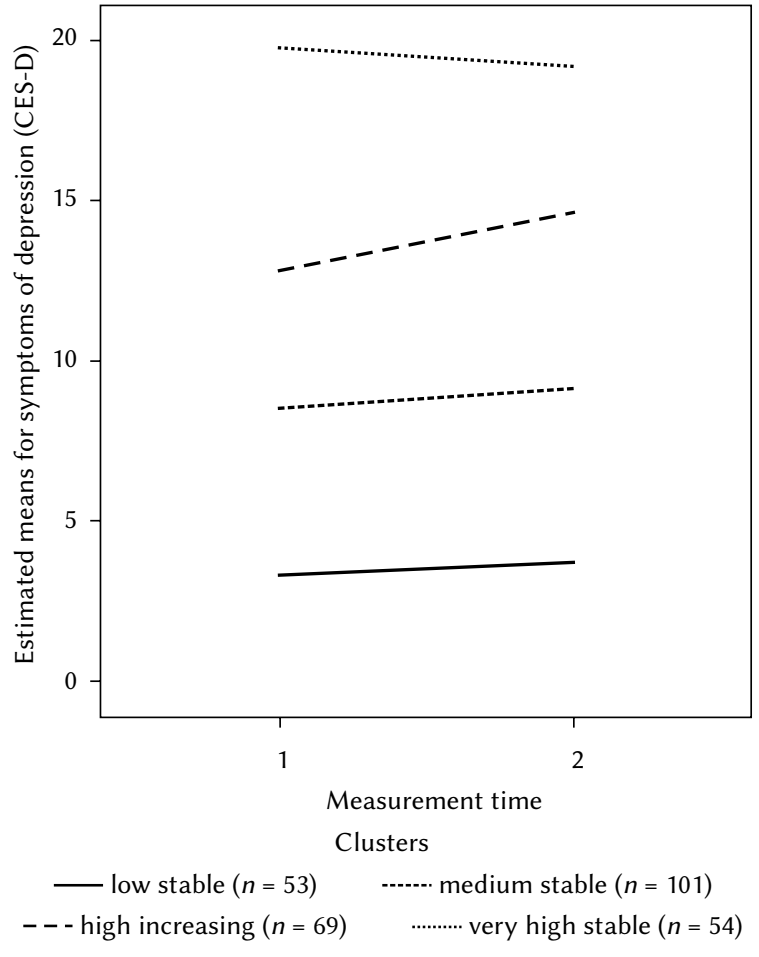

Figure 1. Clusters of depression symptoms over one month (t1-t2).

co-rumination was connected with belonging to the cluster with higher intensity of symptoms. Classes with moderate and low levels of symptoms differed from each other only in terms of brooding.

\section{DISCUSSION}

The aim of this study was to identify clusters differing in terms of the dynamics of depressive symptoms among the elderly within one month, and to find out the correlates of these clusters membership among potential explanatory variables included socio-demographic characteristics of participants, their physical health condition and cognitive coping strategies regarding somatic ailments (reflection, brooding, co-ruminations and positive reappraisal).
Depressive symptom clusters among the elderly 
Table 3

Associations between depressive symptom clusters and demographic and medical variables - results of the $\chi^{2}$ tests

\begin{tabular}{|c|c|c|c|c|c|}
\hline \multirow[t]{2}{*}{ Variable } & $\begin{array}{c}\text { Low stable } \\
\text { symptoms } \\
n=53\end{array}$ & $\begin{array}{c}\text { Moderate } \\
\text { and stable } \\
\text { symptoms } \\
n=101\end{array}$ & $\begin{array}{c}\text { High and } \\
\text { increasing } \\
\text { symptoms } \\
n=69\end{array}$ & $\begin{array}{c}\text { Very high } \\
\text { stable } \\
\text { symptoms } \\
n=54\end{array}$ & \multirow[t]{2}{*}{$\begin{array}{l}p \text {-value with } \\
\text { significant- } \\
\text { ly different } \\
\text { groups }\end{array}$} \\
\hline & (1) & $(2)$ & (3) & (4) & \\
\hline Age, mean years $(S D)$ & $75.89(9.08)$ & $76.92(9.54)$ & $78.09(8.57)$ & $78.87(9.54)$ & .578 \\
\hline Females, \% & 66.00 & 59.40 & 73.90 & 75.00 & .106 \\
\hline $\begin{array}{l}\text { Education, mean years } \\
(S D)\end{array}$ & $12.26(4.11)$ & $10.86(3.69)$ & $10.36(3.60)$ & $10.63(3.72)$ & .192 \\
\hline Cohabiting, $\%$ yes & 32.10 & 15.80 & 10.10 & 11.10 & $\begin{array}{c}.006 \\
(1),(2)>(3),(4)\end{array}$ \\
\hline \multicolumn{6}{|l|}{ Socioeconomic status, $\%$} \\
\hline High & 18.90 & 12.10 & 8.70 & 3.70 & .323 \\
\hline Average & 66.00 & 65.70 & 59.40 & 55.60 & .280 \\
\hline Low & 15.10 & 22.20 & 31.90 & 40.70 & .193 \\
\hline $\begin{array}{l}\text { Number of diseases at } \mathrm{T} 1 \text {, } \\
\text { mean }(S D)\end{array}$ & $4.10(2.21)$ & $3.39(2.57)$ & $5.35(2.76)$ & $5.49(2.74)$ & $\begin{array}{c}<.001 \\
(1),(2)<(3),(4)\end{array}$ \\
\hline $\begin{array}{l}\text { Daily number of medica- } \\
\text { tions used at } \mathrm{T} 1 \text {, mean }(S D)\end{array}$ & $6.12(4.70)$ & $5.32(3.92)$ & $6.91(4.02)$ & $7.83(4.48)$ & $\begin{array}{c}.004 \\
(2)<(4)\end{array}$ \\
\hline $\mathrm{BMI}$ at $\mathrm{T} 1$, mean $(S D)$ & $27.87(3.96)$ & $26.01(4.20)$ & $27.93(5.56)$ & $26.40(5.75)$ & .150 \\
\hline $\begin{array}{l}\text { Residents of care homes, } \\
\% \text { yes }\end{array}$ & 56.60 & 59.40 & 68.10 & 79.60 & $\begin{array}{c}.038 \\
(1),(2)<(4) \\
\end{array}$ \\
\hline
\end{tabular}

Note. BMI - Body Mass Index

The results of the cluster analysis indicate clearly that the group was heterogeneous in terms of the changes in depressive symptoms within a one-month period. The analysis of means for all respondents suggested significant intensification of symptoms. A more detailed analysis revealed, however, that this was a simplification. An increase was observed in only one group, while the remaining three clusters, i.e. the majority of participants, had stable results: low, moderate or very high. What is important, individuals belonging to the 'increasing' cluster had relatively high results in the depression scale already during the first measurement. The cut-off point for clinical depression in the applied version of CES-D was nine points (Byers \& Yaffe, 2011); hence these people may be characterized by deteriorating mental condition, which had already been poor. In these terms, both that group and the group with stable high results should be considered as a clinical population and require appropriate treatment, adjusted to the specificity of the age.

The results seem to confirm the relatively poor condition of Polish seniors. Only $19.00 \%$ of them were individuals with an actually low level of depressive symptoms. It confirms the findings presented earlier (Hank, 2011; HelpAge International, 2013), in whose light some Polish seniors were characterized by worse well-being (including a larger number of depressive symptoms) than their European peers. The obtained results were also congruent with the most up-to-date data of the Social Monitoring Council, concerning the quality of life of Poles. It can be concluded from these data that seniors in Poland (mostly women) are characterized by a significantly lower quality of life than other age groups (see Czapiński, 2013). However, as the report's authors emphasize, the quality of life turned out to depend first of all on the education level of the Poles, which interacts with age (the lower the age, the worse is the education; ibid.). However, in our study the level of depressive symptoms was not related to participants' education. Nevertheless, the homogeneity of the group in this aspect was clear - the majority of respondents had secondary or lower education.

What is interesting, there was no confirmation that gender is a predictor of allocation to certain clusters. The percentage of women in all differentiated groups was similar. Therefore no general tendency was observed for gender to differ among levels of depressive symptoms (women tended to have more symptoms than men, independent of age; see Nolen-Hoeksema, 2001). Although women dominated 
Table 4

Multinomial logistic regression summary table for predicting depressive clusters

\begin{tabular}{lllllll}
\hline$B$ & $S E$ & Wald $\chi^{2}$ & $p$ & OR & $95 \% \mathrm{Cl}$ OR \\
\hline
\end{tabular}

Reference category: very high stable depressive symptoms

Low stable symptoms

\begin{tabular}{|c|c|c|c|c|c|c|c|c|}
\hline Intercept & .83 & .80 & 1.06 & .303 & & & & \\
\hline Number of diseases & -.19 & .09 & 4.68 & .030 & .83 & .70 & .98 & \multirow{4}{*}{$\begin{array}{l}\text { Depressive } \\
\text { symptom clusters } \\
\text { among the elderly }\end{array}$} \\
\hline Brooding & -.80 & .14 & 30.72 & $<.001$ & .45 & .34 & .60 & \\
\hline Co-rumination & -.07 & .11 & 0.40 & .525 & .93 & .74 & 1.16 & \\
\hline Positive reappraisal & .70 & .13 & 27.02 & $<.001$ & 2.01 & 1.55 & 2.62 & \\
\hline
\end{tabular}

Moderate stable symptoms

\begin{tabular}{|c|c|c|c|c|c|c|c|}
\hline Intercept & 1.46 & .66 & 4.89 & .027 & & & \\
\hline Number of diseases & -.21 & .07 & 8.35 & .004 & .81 & .70 & .93 \\
\hline Brooding & -.40 & .11 & 13.66 & $<.001$ & .69 & .54 & .83 \\
\hline Co-rumination & -.13 & .09 & 1.97 & .160 & .87 & .73 & 1.05 \\
\hline Positive reappraisal & .52 & .12 & 19.59 & $<.001$ & 1.67 & 1.33 & 2.11 \\
\hline
\end{tabular}

High and increasing symptoms

$\begin{array}{lrrrrrrr}\text { Intercept } & -.95 & .71 & 1.77 & .183 & & & \\ \text { Number of diseases } & .01 & .07 & 0.03 & .859 & 1.01 & .88 & 1.16 \\ \text { Brooding } & -.25 & .11 & 5.03 & .025 & .78 & .63 & .97 \\ \text { Co-rumination } & .07 & .09 & 0.66 & .416 & 1.08 & .89 & 1.29 \\ \text { Positive reappraisal } & .40 & .12 & 11.85 & .001 & 1.49 & 1.19 & 1.87\end{array}$

Reference category: high and increasing depressive symptoms

Low stable symptoms

$\begin{array}{lrrrrrrr}\text { Intercept } & 1.78 & .78 & 5.17 & .023 & & \\ \text { Number of diseases } & -.20 & .08 & 6.52 & .011 & .82 & .70 & .95 \\ \text { Brooding } & -.55 & .13 & 18.67 & <.001 & .58 & .45 & .74 \\ \text { Co-rumination } & -.15 & .10 & 2.15 & .143 & .86 & .61 & 1.05 \\ \text { Positive reframing } & .30 & .12 & 6.77 & .009 & 1.35 & 1.08 & 1.70 \\ \text { Moderate stable symptoms } & & & & & & & \\ \text { Intercept } & 2.41 & .64 & 14.07 & <.001 & & .80 & .91 \\ \text { Number of diseases } & -.23 & .06 & 11.92 & .001 & .80 & .70 & .02 \\ \text { Brooding } & -.16 & .92 & 2.90 & .089 & .85 & .74 & .95 \\ \text { Co-rumination } & -.21 & .08 & 6.42 & .001 & .81 & .69 & .93 \\ \text { Positive reappraisal } & .12 & .10 & 1.43 & .232 & 1.25 & .93\end{array}$

Reference category: moderate stable depressive symptoms

Low stable symptoms

\begin{tabular}{lrrrrrrr} 
Intercept & -.63 & .67 & 0.89 & .347 & & & \\
Number of diseases & .02 & .07 & 0.10 & .755 & 1.02 & .89 & 1.18 \\
Brooding & -.39 & .12 & 11.00 & .001 & .67 & .53 & .85 \\
Co-rumination & .06 & .09 & 0.43 & .511 & 1.06 & .88 & 1.28 \\
Positive reappraisal & .18 & .10 & 3.48 & .062 & 1.20 & .99 & 1.46 \\
\hline
\end{tabular}

Note. Likelihood ratio test: for the model, $\chi^{2}(12)=96.12, p<.001$; for brooding, $\chi^{2}(3)=41.35, p<.001$; for co-rumination, $\chi^{2}(3)=6.70, p=.080$; for positive reappraisal, $\chi^{2}(3)=34.72, p<.001$; for number of diseases, $\chi^{2}(3)=16.39, p=.001$. Goodness-of-Fit: Pearson $\chi^{2}(756)=817.04, p=.061 ;$ Nagelkerke Pseudo $R^{2}=.32$ 
Aleksandra Kroemeke, Ewa Gruszczyńska in the study, comprising $68.00 \%$ of the sample, similar proportions occur in the population due to the greater lifespan of women. Therefore there is no unequivocal explanation of this phenomenon.

The predictor of the allocation to clusters turned out to be the number of illnesses (multimorbidity), which could be considered as an approximation of the objective health. Paths of influence in this area could be of two kinds: direct, by cognitive representation of one's own illness, and direct, where the illnesses, especially with inflammatory components, may worsen the mood, bypassing psychological mechanisms (Abelaira, Réus, Petronilho, Barichello, \& Quevedo 2014; Maes et al., 2012).

However, the obtained results indicate that this correlation does not have to be linear, when with each subsequent cluster of intensifying depressive symptoms, the number of reported illnesses increases. It rather seems to be a nonlinear process, because exceeding a certain number of illnesses is also accompanied by a definitely worse mood, up to clinical depression. It could be concluded that, compared to other age groups, seniors have a stronger relation between somatic and mental health. The clusters differed in terms of the number of administered drugs, having a partner and the institution; nevertheless, these effects turned out to be insignificant after coping being incorporated in the model.

Regarding the studied coping strategies, the revealed correlations were consistent with the assumptions. The greater the intensity of depressive symptoms, the greater was brooding and the lower was positive reappraisal. In the case of co-ruminations, the relations were less unequivocal. Brooding differentiates the clusters in a nearly linear way, confirming the nonadaptive nature of such coping with health problems (Kraaij et al., 2002; Lyubomirsky \& Tkach, 2003; Nolen-Hoeksema et al., 2008; Thomsen et al., 2005; Watkins, 2008). Its relation with reflection requires further study, though. Despite collinearity testing, on the basis of the correlation coefficient it could be suspected that in the group under study both brooding and reflection played a similar, ruminative role. Meanwhile, positive reappraisal, i.e. reformulation of thinking about a stressor in such a way, so that it is ascribed a positive meaning, changing in turn the emotional response (Folkman \& Moskowitz, 2000), turned out to be associated with less negative mood clusters. However, significant differences occurred only between the clusters of very high symptoms and high increasing ones. This means that positive reappraisal alone is insufficient protection against further intensification of depressive symptoms. This relationship was revealed after taking multimorbidity into account. The studies reveal low efficiency of positive reappraisal in controlled conditions. Nonetheless, the emotional state may be a further limitation of this strategy's effi- ciency; after exceeding a certain level, potentially reflecting the clinical intensification of symptoms, this strategy may be not strong enough to significantly improve the ongoing process of mood deterioration. Therefore moderators of positive reappraisal efficiency should be sought.

Co-ruminations turned out to be distinct from other strategies, especially brooding, which means they should be included in the coping spectrum. Individuals with high and increasing depressive symptoms used these strategies to a larger extent. In these terms, although discussing one's health problems with another person could seem to be seeking emotional social support, in this study group it probably had a similar effect, exacerbating negative mood, observed by Wojciszke, Baryła, Szymków-Sudziarska, Parzuchowski, and Kowalczyk (2009).

Summing up, individuals with a low stable depression level, compared to those with a high stable depression level, differ in terms of brooding and positive reappraisal. In the case of intermediate clusters, these differences are more complex.

The presented research has certain limitations. First of all, the sample has to be considered as non-homogeneous, because it included both seniors staying in residential medical care facilities (so-called nursing homes), and those attending only daily care (activities) in these facilities. However, this potential source of distortions was controlled statistically by testing the moderating function of the institution. No such effect was observed, and the institution turned out to be an insignificant predictor of allocation to the depression clusters in the final model. Secondly, the dynamics of seniors' depressive symptoms were tested within only a one-month period, taking into consideration only measurements of mood. Although this time period is justifiable, e.g. according to ICD-10, a larger number of measurements would allow to analyse the variance not only in terms of the average number of symptoms, but also the trajectory shape, providing data about the 'actual' dynamics of symptoms. Thirdly, the obtained results should be treated as correlative, not cause-and-effect data. Studying the causes of depression changes requires a much more thorough analysis, preferably based on a prospective model.

Despite the aforementioned limitations, it has to be emphasized that this was one of the first research to explore the sub-population of seniors in terms of changes in depressive symptoms and their correlates. It was also one of the first research to test relations between depressive symptoms and brooding, reflection, co-rumination and positive reappraisal. Further studies should be oriented at replicating the stability of the differentiated clusters, seeking other correlates of their membership and recognizing potential moderators of the efficiency of cognitive strategies of coping with health problems among the elderly. 


\section{ENDNOTES}

1 As in the final regression model there was no strategy based on reflection, the models were additionally tested by including in the regression analysis, apart from the other variables: 1) only brooding, 2) only reflection, 3) both these strategies in the form of their summary index. Nagelkerke pseudo $R^{2}$ equalled in these models: .32, .25 , .29 respectively. The model presented in this article was adopted.

The study was co-financed by the Polish Ministry of Science and Higher Education core funding for Statutory Research in the University of Social Sciences and Humanities, Faculty of Psychology, 25504/E-560/M/2013.

\section{References}

Abelaira, H., Réus, G., Petronilho, F., Barichello, T., \& Quevedo, J. (2014). Neuroimmunomodulation in depression: A review of inflammatory cytokines involved in this process. Neurochemical Research [serial online]. Accessed July 23, 2014. DOI: 0.1007/s11064-014-1372-5

Alicke, M. D., Braun, J. C., Glor, J. E., Klotz, M. L., Magee, J., Sederhoim, H., \& Siegel, R. (1992). Complaining behavior in social interaction. Personality and Social Psychology Bulletin, 18, 286-295. DOI: 10.1177/0146167292183004

Arbuckle, J. L. (1995-2010). IBM SPSS AMOS 19. User's guide. Chicago, FL: Amos Development Corporation.

Bonanno, G. A., Kennedy, P., Galatzer-Levy, I. R., Lude, P., \& Elfström, M. L. (2012). Trajectories of resilience, depression, and anxiety following spinal cord injury. Rehabilitation Psychology, 57, 236247. DOI: $10.1037 / \mathrm{a} 0029256$

Börsch-Supan, A., Brugiavini, A., Jürges, H., Kapteyn, A., Mackenbach, J., Siegrist, J., \& Weber G. (2008). First Results from the Survey of Health, Ageing and Retirement in Europe (2004-2007). Starting the Longitudinal Dimension. Mannheim: Mannheim Research Institute for the Economics of Aging.

Brans, K., Koval, P., Verduyn, P., Lim, Y., \& Kuppens, P. (2013). The regulation of negative and positive affect in daily life. Emotion, 13, 926-939. DOI: 10.1037/a0032400

Burwell, R., \& Shirk, S. (2007). Subtypes of rumination in adolescence: associations between brooding, reflection, depressive symptoms, and coping. Journal of Clinical Child and Adolescent Psychology, 36, 56-65. DOI: 10.1080/15374410709336568

Byers, A. L., \& Yaffe, K. (2011). Depression and risk of developing dementia. Nature Reviews Neurology, 7, 323-331. DOI: 10.1038/nrneurol.2011.60

Carver, C. S. (1997). You want to measure coping but your protocol's too long: Consider the Brief
COPE. International Journal of Behavioral Medicine, 4, 92-100.

Central Statistical Office (GUS, 2009). Prognoza ludności na lata 2008-2035 [Population projection for Poland 2008-2035]. Warszawa: Zakład Wydawnictw Statystycznych.

Central Statistical Office (GUS, 2013). Trwanie życia $w 2012$ roku [Life expectancy of Poland 2012]. Warszawa: Zakład Wydawnictw Statystycznych.

Ciesla, J. A., \& Roberts, J. E. (2002). Self-directed thought and response to treatment for depression: A preliminary investigation. Journal of Cognitive Psychotherapy, 16, 435-453. DOI: 10.1891/ jcop.16.4.435.52528

Czapiński, J. (2013). Quality of life in Poland - winners and losers. Social Diagnosis 2013. Objective and subjective Quality of life in Poland [Special issue]. Contemporary Economics, 7, 376-399. DOI: 10.5709/ce.1897-9254.119

Djernes, J. K. (2006). Prevalence and predictors of depression in populations of elderly: A review. Acta Psychiatrica Scandinavica, 113, 372-387.

Dojka, E., Górkiewicz, M., \& Pająk, A. (2003). Wartość pomiarowa skali CES-D do oceny depresji w populacji polskiej [Psychometric value of CES-D scale for the assessment of depression in Polish population]. Psychiatria Polska, 37, 281-292.

EUROSTAT (2010). Demography Report. Retrieved July 20, 2014 from http://epp.eurostat.ec.europa. eu/portal/page/portal/population/documents/ Tab/report.pdf

Folkman, S., \& Moskowitz, J. (2000). Positive affect and the other side of coping. American Psychologist, 55, 647-654.

Garnefski, N., \& Kraaij, V. (2006). Relationships between cognitive emotion regulation strategies and depressive symptoms: A comparative study of five specific samples. Personality and Individual Differences, 40, 1659-1669. DOI: 10.1016/j.paid.2005.12.009

Graham, J. W. (2009). Missing data analysis: Making it work in the real world. Annual Review of Psychology, 60, 549-576. DOI: 10.1146/annurev. psych.58.110405.085530

Gross, J. J. (1998). The emerging field of emotion regulation: An integrative review. Review of General Psychology, 2, 271-299. DOI: 1089-2680/98/\$3.00

Gooding, P. A., Taylor, P. J., \& Tarrier, N. (2012). Perceived extent and effectiveness of reflection and brooding in relation to depressed mood. Cognitive Therapy and Research, 36, 282-289. DOI: 10.1007/ s10608-011-9367-x

Hank, K. (2011). How "successful" do older Europeans age? Findings from SHARE. Journal of Gerontology: Social Sciences, 66B, 230-236. DOI: 10.1093/ geronb/gbq089

Helgeson, V. S., Helgeson, V. S., Reynolds, K. A., \& Tomich, P. L. (2006). A meta-analytic review of benefit finding and growth. Journal of Consult-
Depressive symptom clusters among the elderly 
ing and Clinical Psychology, 74, 797-816. DOI: 10.1037/0022-006X.74.5.797

HelpAge International (2013). Global AgeWatch Index 2013: Insight report. Retrieved July 20, 2014, from http://www.helpage.org/global-agewatch/\#

Juczyński, Z. (2009). Narzędzia pomiaru w promocji i psychologii zdrowia [Measurement tools in the health promotion and psychology]. Warszawa: Pracownia Testów Psychologicznych PTP.

Kirchberger, I., Meisinger, C., Heier, M., Zimmermann, A., Thorand, B., Autenrieth, C., Peters, A.,
Aleksandra Kroemeke, Ewa Gruszczyńska Ladwig, K. H., \& Döring, A. (2012). Patterns of multimorbidity in the aged population. Results from the KORA-Age study. PLoS One, 7, e30556. DOI: 10.1371/journal.pone.0030556

Kraaij, V. V., Pruymboom, E. E., \& Garnefski, N. N. (2002). Cognitive coping and depressive symptoms in the elderly: A longitudinal study. Aging \& Mental Health, 6, 275-281. DOI: 10.1080/13607860220142387

Lazarus, R. S., \& Folkman, S. (1984). Stress, appraisal, and coping. New York: Springer Publishing.

Lyubomirsky, S., \& Nolen-Hoeksema, S. (1993). Selfperpetuating properties of dysphoric rumination. Journal of Personality and Social Psychology, 65, 339-349. DOI: 10.1037/0022-3514.65.2.339

Lyubomirsky, S., \& Tkach, C. (2003). The consequences of dysphoric rumination. In: C. Papageorgiou, \& A. Wells (eds.), Rumination: Nature, theory, and treatment of negative thinking in depression (pp. 21-41). Chichester, England: John Wiley \& Sons.

Maes, M., Berk, M., Goehler, L., Song, C., Anderson, G., Gałecki, P., \& Leonard, B. (2012). Depression and sickness behavior are Janus-faced responses to shared inflammatory pathways. BMC Medicine, 10, 66 [serial online]. Accessed July 23, 2014. DOI: 10.1186/1741-7015-10-66

Marroquin, B., Fontes, M., Scilletta, A., \& Miranda, R. (2010). Ruminative subtypes and coping responses: Pathways to depressive symptoms. Cognition and Emotion, 24, 1446-1455. DOI: $10.1080 / 02699930903510212$

Mooi, E., \& Sarstedt, M. (2011). A Concise Guide to Market Research. The Process, Data, and Methods Using IBM SPSS Statistics. Berlin Heidelberg: Springer-Verlag.

Nolen-Hoeksema, S. (2001). Gender differences in depression. Current Directions in Psychology Science, 10, 173-176.

Nolen-Hoeksema, S., Wisco, B. E., \& Lyubomirsky, S. (2008). Rethinking rumination. Perspectives on Psychological Science, 3, 400-424. DOI: 10.1111/j.17456924.2008.00088.x

Radloff, L. S. (1977). The CES-D Scale: A self-report depression scale for research in the general population. Applied Psychological Measurement, 1, 385401. DOI: $10.1177 / 014662167700100306$

Rechel, B., Grundy, E., Robine, J., Cylus, J., Mackenbach, J., Knai, C., \& McKee, M. (2013). Ageing in the European Union. The Lancet, 381, 1312-1322. DOI: 10.1016/S0140-6736(12)62087-X

Rewston, C., Clarke, C., Moniz-Cook, E., \& Waddington, R. (2007). Distinguishing worry from rumination in older people: a preliminary investigation. Aging and Mental Health, 11, 604-611. DOI: 10.1080/13607860701529619

Roberts, R. E., Kaplan, G. A., Shema, S. J., \& Strawbridge, W. J. (1997). Does growing old increase the risk for depression? The American Journal of Psychiatry, 154, 1384-1390.

Rose, A. J. (2002). Co-rumination in the friendships of girls and boys. Child Development, 73, 1830-1843.

Rose, A. J., Carlson, W., \& Waller, E. M. (2007). Prospective associations of co-rumination with friendship and emotional adjustment: Considering the socioemotional trade-offs of co-rumination. Developmental Psychology, 43, 1019-1031. DOI: 0.1037/0012-1649.43.4.1019

Schoofs, H., Hermans, D., \& Raes, F. (2010). Brooding and reflection as subtypes of rumination: Evidence from confirmatory factor analysis in nonclinical samples using the Dutch Ruminative Response Scale. Journal of Psychopathology and Behavioral Assessment, 32, 609-617. DOI: 10.1007/ s10862-010-9182-9

Steuden, S. (2011). Psychologia starzenia się i starości [Psychology of Ageing and Old Age]. Warszawa: Wydawnictwo Naukowe PWN.

Thomsen, D., Mehlsen, M., Viidik, A., Sommerlund, B., $\&$ Zachariae, R. (2005). Age and gender differences in negative affect - Is there a role for emotion regulation? Personality and Individual Differences, 38, 1935-1946. DOI: 10.1016/j.paid.2004.12.001

Treynor, W., Gonzalez, R., \& Nolen-Hoeksema, S. (2003). Rumination reconsidered: A psychometric analysis. Cognitive Therapy and Research, 27, 247259. DOI: 10.1023/A:1023910315561

Troy, A. S., Shallcross, A. J., \& Mauss, I. B. (2013). A person-by-situation approach to emotion regulation: Cognitive reappraisal can either help or hurt, depending on the context. Psychological Science, 24, 2505-2514. DOI: 10.1177/0956797613496434

Watkins, E. R. (2008). Constructive and unconstructive repetitive thought. Psychological Bulletin, 134, 163-206. DOI: 10.1037/0033-2909.134.2.163

Whitmer, A., \& Gotlib, I. H. (2011). Brooding and reflection reconsidered: A factor analytic examination of rumination in currently depressed, formerly depressed, and never depressed individuals. Cognitive Therapy And Research, 35, 99-107. DOI: 10.1007/s10608-011-9361-3

Wojciszke, B., Baryła, W., Szymków-Sudziarska, A., Parzuchowski, M., \& Kowalczyk, K. (2009). Saying is experiencing: Affective consequences of complaining and affirmation. Polish Psychological Bulletin, 40, 74-84. DOI: 10.2478/s10059-009-0008-0 
World Health Organization (1992). ICD-10 Classifications of Mental and Behavioural Disorder: Clinical Descriptions and Diagnostic Guidelines. Geneva: World Health Organization.

World Health Organization (2011). Global Health and Aging. Geneva: World Health Organization. Retrieved July 20, 2014 from http://www.who.int/ ageing/publications/global_health/en/

Ziarko, M., Kaczmarek, Ł. D., \& Haładzińki, P. (2013). Polish version of Centre for Epidemiological Studies Depression Scale (CES-D): results of a preliminary study on the psychometric properties of the scale. Current Issues in Personality Psychology, 1, 51-61. DOI: 10.5114/cipp.2013.40637

Depressive

symptom clusters among the elderly 